\title{
Papa chilena, el vodka y su influencia en la Segunda Guerra Mundial: frente ruso
}

\author{
Chilean potato, vodka and its influence in the Second World War: Russian front \\ Ernesto Ponce López ${ }^{1}$
}

\begin{abstract}
RESUMEN
Existen evidencias científicas de que la papa chilena originaria de Chiloé es la ascendiente de las actuales papas europeas. Ellas constituyeron uno de los alimentos principales que sustentaron al Ejército Rojo durante la Segunda Guerra Mundial. No sólo como papas cocinadas, sino que a partir de ellas se fabricaba vodka, el licor típico de Rusia. Entre otros factores, este licor permitió luchar y permanecer en la intemperie a unidades completas, a veces a temperaturas de $40{ }^{\circ} \mathrm{C}$ bajo cero. Fue un aliciente para soldados que combatían bajo condiciones precarias y frente a enemigos aguerridos, como los soldados alemanes. Fue tan importante su contribución a la victoria, que el suministro fue reglamentado por Ordenanzas del Ejército. Aun en lugares tan lejanos y de difícil acceso como Stalingrado, no faltó esta bebida alcohólica. La contribución rusa en la victoria fue reconocida por Sir Winston Churchill, quien indicó que gracias al Ejército Rojo se derrotó a las fuerzas alemanas: fueron las 300 divisiones soviéticas las que desbarataron a las cerca de 100 divisiones, de las disciplinadas tropas del III Reich, en el Frente Oriental. Esto generó un cambio notable en la política y en la historia del mundo.
\end{abstract}

Palabras clave: papas, horticultura, vodka, historia.

\section{ABSTRACT}

There is scientific evidence that potatoes from Chiloe, Chile were the ancestor of the current European potato. They were one of the main foods that supported the Red Army during World War II. Not only as cooked potatoes, but vodka was also made from them, the typical Russian liquor. Among other factors, this liquor allowed army groups to fight and remain outdoors, sometimes at temperatures of $-40^{\circ}$ Celsius degrees. It was an incentive for soldiers who fought under precarious conditions facing hardened enemies, as were the German soldiers. It was such an important contribution to victory that the supply was regulated by military orders. Even places as far away and inaccessible as Stalingrad did not lack vodka. The Russian contribution to victory was recognized by Sir Winston Churchill, who said that with the Red Army the German forces were defeated; 300 Soviet divisions that destroyed at about 100 German divisions, the disciplined troops of the Third Reich, on the Eastern Front. This led to a noticeable change in politics and world history.

Key words: potatoes, horticulture, vodka, history.

\section{Introducción}

Los europeos conocieron esta planta a mediados del siglo XVI, con la conquista del Imperio Inca, Poma de Ayala [1]. Su nombre "papa" proviene del Quechua. No hay precisión sobre la llegada de la papa a Europa. Sí hay certeza que se difundió principalmente por dos vías: una por Irlanda, Inglaterra y los Países Bajos y otra por Portugal, España, Francia e Italia. Hoy es una parte importante de la nutrición en el mundo. Más que el maíz y otras plantas traídas de América, ninguno de los nuevos vegetales ha sido tan esencial para Europa como la papa. En este continente fue la comida básica de los pobres (el pintor Vincent van Gogh lo representó muy bien en su óleo de 1885: Los comedores de papas). No sólo ha alimentado a los pueblos, sino también sirve de alimentación para el ganado. En Irlanda se cultivaron papas desde inicios del siglo XVII, pues era un cultivo ideal para una isla azotada por la miseria; por años las papas fueron la principal fuente de alimento de los agricultores y el pueblo. Las introducciones de papas chilenas hacia 1580 habrían sido originarias de las papas europeas: piel

1 Escuela Universitaria de Ingeniería Mecánica. Universidad de Tarapacá. Arica. Chile. Email: eponce60@ gmail.com

Fecha de Recepción: 03 Junio, 2011.

Fecha de Aceptación: 26 Septiembre, 2011. 
marrón e interior amarillo, con flores blancas en la planta. Se adaptaron bien a las características ecológicas de Irlanda, que son parecidas a las encontradas en el Sur de Chile: clima frío, lluvioso y geografía de colinas.

En Prusia, Federico II difundió el consumo de la papa con un mandato, fechado el 24 de marzo de 1756, en que publicó una circular ordenando el cultivo de este tubérculo.

Las primeras referencias sobre la papa en Chile aparecen en las misivas al Emperador Carlos $\mathrm{V}$, enviadas por el Gobernador Pedro de Valdivia, Zapater [2].

La exploración del Capitán Juan de Ladrillero del litoral chileno desde Valdivia hasta el Estrecho de Magallanes está en las relaciones de los años 1558 del escribano Miguel de Goicueta y de 1559 por Ladrillero. En ambas se menciona que en Chiloé la papa era un alimento importante en la dieta de los indios.

El primer informe detallado del cultivo de la papa en América lo hace Fray Vázquez de Espinoza en "Compendio y descripción de las Indias Occidentales", en 1628. Se indica su presencia desde Ecuador, Perú, Bolivia, Argentina, Paraguay y Chile, aquí menciona la ciudad de Castro en Chiloé.

En el siglo XVII, Vicente Carballo Goyeneche en "Descripción Histórico-Geográfica del Reino de Chile", escribe de las variedades de estas papas de Chiloé, mencionando que había unas treinta.

En 1836 el naturalista Claudio Gay recolectó en Chiloé 45 variedades de papas.

En 1926, el botánico ruso Juzepczuk viajó por Chile analizando y recogiendo muestras en el Centro, Sur y la Isla Grande de Chiloé. Ese mismo año inició sus contactos con la papa de Chiloé, otro genetista ruso y gran estudioso de la papa chilota, S. Bukasov [3], [4], [5]. Analizando el material concluyó en 1937 que "las papas chilotas presentaban un hábito de crecimiento y comportamiento fotoperiódico muy semejante a las variedades europeas". De allí postuló la teoría de que la papa europea proviene de la papa de la Isla Grande de Chiloé y de las islas adyacentes. Los especímenes en su mayoría fueron recolectados en el sector de Yutuy, frente a la ciudad de Castro.

En 1949, Alfonso Castronovo realiza una clasificación de 113 formas endémicas de papas recolectadas en Chiloé.

En 1989 el Centro de Educación y Tecnología (CET), Chiloé, inició la formación de un banco de papas chilotas en su sede de Notuco, Comuna de Chonchi. Se realizan programas de trabajo con comunidades de campesinos e indígenas, a fin de resguardar este legado.

Entre los años veinte a treinta del siglo XX el genetista y biogeógrafo ruso Nikolai Vavilov y sus asociados [6] crearon el concepto de centros de diversidad. Entre los centros de origen de la papa están las Islas de Chiloé y de Los Chonos: "ellas cumplen con todos los requisitos y condiciones que caracterizan un genocentro: como aislamiento geográfico y aislamiento climático natural del país; métodos rudimentarios de agricultura; el haberse originado otras plantas útiles en el área y gran diversidad de variedades indígenas primitivas". Por último, lo más importante y que ha sido demostrado sustancialmente, es la presencia de papas silvestres en la zona.

El naturalistas ruso A.G. Sykin [7] dice que las variedades que existen en las islas de Chiloé y de Los Chonos creciendo en condiciones naturales son silvestres, porque tienen estolones largos de hasta $90 \mathrm{~cm}$ y tubérculos pequeños y sin sabor. Hace notar que las semejanzas morfológicas y citológicas entre las papas silvestres de Chiloé, recolectadas y descritas por diferentes científicos, y las formas indígenas primitivas, son evidencia de su estrecha relación fitogenética. La presencia de papas silvestres en la poco menos que inaccesible geografía del Sur chileno, lejos de enclaves humanos, es clara evidencia de que estas formas de papa no provienen del norte (Perú) y de que son autóctonas.

Según el experto de la Universidad Austral, Profesor Andrés Contreras, [8]: "Los antecedentes que indican la mayor antigüedad de papas en Chile son aportados por Ugent y otros que en 1987 señalaron que en el sitio arqueológico de Monte Verde, con una data de 13.000 años, se encontraron especímenes de papa y que el estado en que se encontraron indicaría su consumo por pueblos aborígenes".

Según este mismo científico, basándose en otros autores, afirma que la variedad "Rough Purple Chili" introducida en el período 1848-1851 en EE.UU. y luego en Europa ha sido de las más valiosas, y progenitora de un incalculable número de cultivos en todo el mundo. Hasta el año 1932 se conocían más de 650 cultivares que tenían un grado de parentesco con la variedad chilena. El botánico Fuess indica que el antiguo grupo de ejemplares inglés-norteamericano provendría de material chileno, que alrededor de 1580 habría sido llevado de Chile a Inglaterra. También Siebeneick reporta 
que la variedad "Patterson Victoria" fue introducida en el siglo XVII de Chile a Irlanda, y después a Inglaterra. La variedad "Daber", introducida en 1830 a Alemania, es también una muy importante y antigua variedad, que según autores como Hawkes y Glendinnig pertenece probablemente a una forma primitiva cultivada en Chile. Si así fuese (incluyendo otras líneas desarrolladas por Müller, a través de la "Chilote Indianer") más del 80\% de los actuales cultivos de papa del mundo tendrían parentesco con las originarias de Chile", Contreras [8].

Además, por las apariencias externas, las papas modernas lucen tener ascendientes chilenos. Las plantas europeas de papa tienen hojas anchas, como las variedades chilenas, y ambas son adaptadas al día largo, esto significa que necesitan días más largos en verano para formar los tubérculos, Papas nativas [9].

Hay investigadores que afirman que las papas chilenas como las andinas fueron cultivadas en Europa décadas antes y después de la Gran Hambruna Irlandesa de las patatas, en el siglo XIX, donde la epidemia de hongo "Phytophthora Infestans", o Tizón Tardío, las hizo casi desaparecer de Europa. Esto es cierto; sin embargo, estudios recientes, basados en el análisis genético del tubérculo, indican que en Chile está el origen de las papas que hoy se cultivan en el continente europeo, fuente: USDA, United States Department of Agriculture, Agricultural Research Service, ARS. Unidad de Investigación de Cosechas de Legumbres [10].

Mercedes Ames y David Spooner han publicado recientemente en la revista American Journal of Botany [11]. Ambos, investigadores de la Universidad de Wisconsin-Madison, demuestran que el 99\% de las variedades que se cultivan en Europa proceden de Chile. Se eligieron 64 muestras de papas europeas que crecieron entre los años 1700 y 1910. Muchas de las muestras tenían más de 300 años y no estaban bien preservadas. Hubo que utilizar ingenio para extraer el ADN de esos antiguos especímenes.

La Organización de las Naciones Unidas (ONU) dispuso que el año 2008 fuese declarado el Año Internacional de la Patata, por ello la National Science Foundation financió el proyecto. Se extrajo exitosamente el ADN de 49 muestras. Se marcó cada una mediante un marcador genético, para distinguir las cepas procedentes de los Andes, de las originarias del sur de Chile. Se determinó que las primeras papas cultivadas sistemáticamente en Europa venían de la subregión andina. La variedad chilena llegó después. Las dos especies convivieron hasta 1892, esto indica que no todas las plantas andinas se perdieron por la plaga del hongo. A partir de 1900, hubo un proceso de colonización, al término del cual la variedad chilena fue la dominante, hasta erradicar a la papa andina.

El equipo de Wisconsin-Madison opina que los europeos introdujeron las papas chilenas con la certeza que éstas se adaptarían mejor a las condiciones ambientales de Europa. Su éxito y expansión demuestra que estaban en lo cierto.

\section{Materiales y Método}

En este trabajo se ha revisado la literatura hortícola, histórica y técnica más relevante, relacionada con la papa, empezando con uno de los principales cronistas, Guamán Poma de Ayala, desde los años 1583 hasta literatura especializada de 2011. La revisión se hizo mediante búsquedas en portales tecnológicos de Internet, junto con datos obtenidos de organizaciones oficiales, como USDA, United States Department of Agriculture, Agricultural Research Service, ARS, y literatura obtenida de bibliotecas no virtuales. Las publicaciones consideradas pertinentes se han ordenado y analizado.

\section{Importancia de los cultivos de papas en la Unión Soviética}

Desde su introducción en Rusia de este tubérculo, ha formado parte de la dieta de campesinos y el pueblo. Su cultivo y cosecha se puede realizar sin herramientas especiales. El ganado no causa ningún daño a la planta, porque las papas están bajo tierra. La mayor ventaja es que se obtiene un mayor rendimiento por hectárea, frente a los cultivos de cereales. La preparación de la papa es más sencilla que la de estos últimos: las papas no se trillan ni muelen, lo que sí es necesario para hacer pan.

Las papas contienen, entre otros, las calorías necesarias, oligoelementos y vitaminas, que ningún otro alimento a su alcance les podían proporcionar.

Puede cultivarse en las estepas, durante el período apropiado del año. Después de la Revolución, botánicos rusos viajaron por el mundo, en especial por Sudamérica, buscando variedades que se adaptasen a su clima frío. La finalidad era la de llevar a la URSS variedades nuevas, que mejoraran la alimentación de los muchos pueblos de las repúblicas soviéticas. El científico Nikolai Vavilov [6] 
escribió un interesante libro sobre las variedades halladas en el Nuevo Mundo y Asia (1920-1930), hay un capítulo dedicado a la importancia de los cultivos precolombinos, también habla de papas oriundas de Chiloé.

\section{El vodka}

Es un producto destilado proveniente de la papa. El vodka producido en Rusia contenía $40 \%$ de alcohol. Su aporte calórico al organismo por cada $100 \mathrm{~g}$ es de $315 \mathrm{kcal}$. Carece de la toxicidad de los aguardientes destilados en alambiques de cobre. Está compuesto sólo por agua y etanol, no teniendo un sabor particular. El agua pura empleada en su fabricación proviene de manantiales o hielos derretidos. Aun está en discusión si fueron los rusos o los polacos quienes lo inventaron. La intención pudo ser el producir una concentración tan elevada de alcohol, que no se congelase fácilmente, porque el alcohol congela a temperaturas inferiores que el agua. Quien masificó la idea del aguardiente sin sabor fue San Pedro Smirnoff, encontrando una gran acogida. Se considera uno de los menos perjudiciales licores, porque se filtra con carbón de madera de abedul o manzano, que retiene impurezas. Este efecto se nota porque no produce dolores de cabeza ni malestares al día siguiente de la ingesta. En los países del Este europeo la palabra vodka comienza a emplearse sólo desde el siglo XVII, en Rusia significa algo así como "agüita" [12].

\section{Fabricación del vodka a partir de las papas}

\section{Materias primas}

En promedio, con $830 \mathrm{~kg}$ de papas, de $18 \%$ de fécula, se generan 100 litros de alcohol puro. Con papas de 20\% de fécula es posible obtener 110 litros. Además para obtener 1001 de alcohol se precisan 19,5 kg de cebada: $15 \mathrm{~kg}$ para la sacarificación y 4,5 kg para la levadura. En cuanto al consumo de energía para producir vapor, son necesarias $1.134 .000 \mathrm{kcal}$ que generarían unos $1.400 \mathrm{~kg}$ de vapor, en unas 4 horas de proceso. El consumo de agua varía de 480 a 960 litros, dependiendo del número de sacarificaciones (una hasta tres, variando el tiempo desde 4 a 10 horas de proceso) Hütte [13].
Para el procesamiento se requieren las papas, que aportan materia amilácea, fécula. También los cereales que aportan el almidón (cebada), transformado en azúcar por las diastasas que produce la germinación. Al adicionar la levadura, se descompone el azúcar en alcohol y anhídrido carbónico. La solución de agua y alcohol obtenida se destila varias veces hasta obtener la concentración deseada.

\section{Proceso de fabricación}

\section{Preparación del malte}

El objetivo es formar en el grano de cebada las diastasas que contienen la enzima sacarificadora del almidón. Para ello se remoja el grano en depósitos, removiendo el grano con aire o agitadores, el proceso dura dos días, allí absorbe agua en proporción de $30 \%$ en volumen. Luego se lleva a la era de germinación, en una bodega con poca luz y piso de baldosas. Se requieren $25 \mathrm{~m}^{2}$ de superficie por cada mil litros de material humectado, con unos $10 \mathrm{~cm}$ de espesor. El tiempo de germinación es de unos 12 días (cuando las plúmulas alcanzan unos 2 $\mathrm{cm}$ ). Una vez finalizada esta etapa, el malte verde es triturado.

\section{Cocción de las papas}

Las papas se lavan en un estanque de baja profundidad, luego son izadas por un elevador hasta una tolva. Allí son pesadas y enviadas al cocedor. El objetivo es destruir la capa que recubre las células para que la fécula se convierta en engrudo. Se cuecen a una presión de 3 atm por 30 minutos, se deja salir el agua y las papas se envían a un depósito mezclador, donde se enfrían.

\section{Mezclado y sacarificación}

En el mezclador previamente se ha introducido el malte molido, combinado con agua fría. Al recibir las papas cocidas se activa el agitador y se enfría externamente el depósito, mediante un serpentín o camisa de agua. La temperatura no debe ser superior a $59^{\circ} \mathrm{C}$, para que se eliminen las bacterias que puedan inhibir la fermentación y no se inactiven las diastasas. El proceso dura unos 30 minutos. 


\section{Proceso del mosto}

Se hace descender la temperatura entre 15 a $18{ }^{\circ} \mathrm{C}$, en un tiempo no superior a 45 minutos, para evitar contagio bacteriano en la fermentación. Luego se conduce el mosto dulce al depósito de fermentación, donde se produce alcohol etílico y $\mathrm{CO}_{2}$. El proceso dura unos 3 días, no debiendo subir la temperatura sobre $25^{\circ} \mathrm{C}$.

\section{Destilación del mosto}

Se hace hervir el líquido y por destilaciones sucesivas (en una torre de condensación) se concentra el alcohol: la primera alcanza al $28 \%$ y la segunda $50 \%$, con eso basta para el vodka (para otros fines hay una tercera y hasta una cuarta destilación). Finalmente, para el consumo humano como bebida alcohólica, el producto es filtrado en filtros de carbón activado (de maderas duras), donde se eliminan metales pesados y otros contaminantes.

\section{Motivos del consumo de vodka en el Ejército Rojo}

La violenta invasión alemana había provocado el colapso de suministros de toda índole. Tres millones de soldados rusos habían caído prisioneros en los primeros meses del conflicto. Las condiciones de vida eran infrahumanas, faltaban alimentos, vestuario, armas y municiones. Gran parte de la industria se trasladó tras los montes Urales, lejos de la aviación enemiga. La tierra era arrasada para no dejar nada a los invasores. El Ejército de la Unión Soviética era incapaz de sobreponerse a la estrategia y tácticas de la llamada Guerra Relámpago. Sólo quedaba resistir en las ciudades. Hasta se formaron batallones de mujeres combatientes, que se comportaron heroicamente y murieron luchando. Bajo esta aplastante gran ola de modernas y organizadas fuerzas atacantes, Stalin tomó medidas que nunca habría aplicado en época de paz: libertad para el culto Ortodoxo, se abrieron las iglesias que antes habían sido cuarteles (con esto la moral del pueblo se acrecentaba); decreto de guerra total donde niños y mujeres trabajaban reconstruyendo puentes, transportando municiones y cualquier género de trabajos que antes hacían los hombres. Entre otras medidas, aprobó y reglamentó la entrega dosificada de licor a los combatientes, para elevar su estado de ánimo.
Su idea, que provenía del conocimiento que tenía del pueblo ruso, dio resultados, tanto en el frente como tras las líneas germanas, en la lucha de guerrillas. Sobre esto último informaba un alto oficial alemán: "Por aquí, allá y acullá, en la estepa, hay tanques semidestruidos. Están ocupados por uno o dos francotiradores rusos. Se mantienen por semanas con una bolsa de patatas cocidas, una botella de vodka, un fusil con mira telescópica y algunas municiones. Son un problema mortal para cualquier alemán que cruce frente a ellos".

Otro motivo fue evitar el consumo de licores clandestinos, a veces elaborados con alcohol metílico. La tensión de la batalla era tan grande que los soldados buscaban licor en cualquier parte. Se bebía alcohol industrial e incluso el anticongelante, después de pasarlo por el filtro de carbón activado de una máscara antigás. El resultado podía ser peor que el agudo dolor de cabeza. Muchos se recobraron porque eran jóvenes y fuertes, no lo consumían con frecuencia, pero algunos se quedaron ciegos, Beevor [14].

\section{Reglamentación para el consumo de vodka en el frente ruso}

Las ordenanzas se han copiado de las traducciones del ruso al español, obtenidas de www.1jma. $\mathrm{dk} /$ articles/1jmaarticlesvodka.html, [12]:

Orden de la distribución por parte de la intendencia. Para efectivos de la primera línea de los militares del Ejército Rojo en la cantidad de vodka de $100 \mathrm{~g}$ por día.

$\mathrm{N}^{\circ} 032025$ de agosto de 1941.

Según el Comité Estatal de Defensa en el Decreto de 22 de agosto de 1941, por la presente orden:

1. Desde el 1 de septiembre de 1941 los militares y comandantes, destacados en primera línea deben recibir $100 \mathrm{~g}$ de vodka de 40 grados por persona y día. Los aviadores de la Fuerza Aérea, que cumplan funciones de combate, y el personal técnico, que mantiene el campo de las pistas de aterrizaje, debe recibir el vodka del mismo modo lo reciben las tropas que luchan en primera línea.

2. Los Consejos de las Fuerzas Armadas y Ejércitos Frentes deberían adoptar las medidas necesarias para: A. Organizar la distribución de vodka exclusivamente para los contingentes que son definidos por el Comité Estatal de 
Defensa y supervisar estrictamente el más exacto cumplimiento de la orden. B. Garantizar la entrega oportuna de vodka en la primera línea de combate y organizar un servicio de vigilancia fiable de las reservas de vodka. $C$. A expensas de la distribución de las unidades y formaciones, la selección de personal especial debe ser considerado responsable de la correcta distribución de las partes de vodka, deben también llevar la contabilidad de los gastos y realizar los balances que ocasione la distribución del vodka. D. Se da orden a los Intendentes de los Frentes entregar una vez cada diez días al Intendente Principal de la Junta, la información sobre los restos de vodka, y para componer las aplicaciones necesarias para la cantidad de vodka cada mes, antes del día 25. Como base de dicha solicitud debe tenerse en cuenta el número exacto de las tropas de primera línea, y ser efectuada por el Consejo Militar de los Ejércitos del Frente.

3. La cantidad necesaria de vodka en el mes de septiembre debe ser establecida por el Intendente Jefe del Ejército Rojo, sin la presentación de las solicitudes de los Frentes y Ejércitos.

La orden debe hacerse válida a través de telégrafo.

Posteriormente, en mayo de 1942, se limita el vodka sólo al personal destacado.

Adjunto del Comisario del Pueblo de Defensa: Teniente General del Servicio de Intendencia Khruljev.

GOKO N-1227 del 11 de mayo de 1942

Moscú, Kremlin

En cuanto a la distribución de vodka a la Fuerza Móvil del Ejército Rojo:

1. Desde el 15 de mayo de 1942 la distribución masiva de vodka entre el personal de la Fuerza de Campo, debe ser abolida.

2. La actual distribución de vodka se debe mantener solamente entre las tropas desplazadas a primera línea, que hayan realizado con éxito operaciones contra los invasores alemanes. La parte de vodka a partir de ahora deberá ser aumentada a los 200 g por soldado y día.

Para lograr este objetivo, todos los meses el vodka debe ser entregado a la disposición del Frente de Mando, en la cantidad del $20 \%$ de la dotación total del Ejército, para la primera línea de combate.

3. El personal restante de las tropas de primera línea de combate debe recibir vodka en la cantidad de 100 gramos para cada militar, exclusivamente en los días de festivos.

4. El Comité Estatal de Defensa suprime por tanto el Decreto N 562 cc, de 22 de agosto de 1941.

El 12 de junio de 1942, el propio José Stalin aclara y ordena:

Comité Estatal de Defensa Presidente I. Stalin

Orden relativa a las normas de vodka mantenimiento y Distribución entre las tropas desplazadas al campo de batalla.

N 0470 del 12 de junio de 1942

A pesar de las repetidas orientaciones y órdenes explícitas acerca de la distribución de vodka entre las tropas, de acuerdo con la realidad existen numerosos casos de distribución ilegal.

Así, el vodka en ocasiones es robado por los funcionarios, y comandantes de las unidades. Algunos comandantes de las unidades y formaciones, así como oficiales del Estado Mayor, reciben vodka de los almacenes, haciendo caso omiso de las órdenes y normas establecidas.

El control de los gastos de vodka se realiza por el Consejo Militar; sin embargo, tras recontar el vodka en cuanto a las cantidades y a las unidades de los almacenes, muestra una deficiencia considerable.

Según el Comité Estatal de Defensa de Decreto del 6 de junio de este año GOKO-1889c, por la presente orden se establece:

1. La distribución de vodka se hará en la cantidad de $100 \mathrm{~g}$ para cada militar de forma diaria para las tropas que realicen operaciones ofensivas.

2. El personal restante de las tropas de primera línea debe recibir vodka en la cantidad de 100 gramos a cada militar exclusivamente en los siguientes días de fiesta:

- Gran Revolución Socialista de Octubre aniversario $\left(7^{\circ}\right.$ y 8 de noviembre)

- Día de la Constitución (5 de diciembre )

- Día de Año Nuevo (1 de enero)

- Día del Ejército (23 de febrero)

- Día Internacional del Trabajo (1 y 2 de mayo)

- Día de la Unión (19 de julio)

- Día de la Aviación (16 a de agosto)

- Día Internacional de la Juventud (6 de septiembre), también se repartirán el día de la Unidad (la fecha de formación de la unidad).

3. La distribución de vodka entre el personal de los Ejércitos y de otras formaciones debe ser coordinada con el Jefe de Intendencia Oficial 
del Ejército Rojo, de acuerdo a las instrucciones del Estado Mayor y de las solicitudes de los Consejos de Frentes Militares.

4. Para el mantenimiento de vodka se crearán almacenes especiales, en el Frente. El gerente de la bodega y un almacenista deben elegirse destacando especialmente por ser honestos, personal fiable, que se encuentre en condiciones de garantizar la seguridad de las existencias de vodka. Los depósitos deben estar herméticamente sellados hasta el momento de la distribución y se debe mantener guardias en las puertas, eligiendo entre la tropa a los soldados más fiables.

5. Los jefes de intendencia deben inscribir todas las existencias disponibles de vodka, desde el 15 de junio y la transferencia de ese stock con destino a los almacenes del frente, será responsabilidad de ellos

6. El registró y la distribución de vodka debe ser realizada por el Jefe del Ejército Rojo de la Junta Principal, que se encargará de la distribución a los jefes de las juntas y departamentos, que a su vez distribuirán a los distintos Frentes del Ejércitos, de acuerdo a las instrucciones citadas.

7. El Consejo de las Fuerzas Armadas y el Ejército debe ser considerado como responsable de la correcta conservación, de los gastos y la contabilidad del vodka así como del embalaje de las botellas.

8. Esta orden se hará valida a través de telégrafo.

9. La Orden N 0373 de 1942 emitida por el Comité Estatal de Defensa es abolida.

\section{Consumo mínimo estimado de vodka y papas en el Ejército Rojo}

\section{En algunas batallas importantes ${ }^{\#}$}

Las cifras son impresionantes, si se piensa que el volumen de una piscina olímpica de 50×25×2 m es de 2.500.000 litros, los cálculos más conservadores indicarían que sólo en la batalla de Stalingrado se superó esa cifra en vodka.

\section{Consumo estimado de vodka y papas en el Ejército Rojo durante la guerra}

El tiempo involucrado se considera a partir de la Orden $\mathrm{N}^{\circ} 0320$ del 25 de agosto de 1941, hasta la toma de Berlín, el 2 de mayo de 1945. El número de combatientes se refiere sólo a los soldados, no al numeroso personal civil de apoyo. Basándose en datos del mismo Ejército Alemán, se habían identificado a lo menos 300 divisiones soviéticas en el Frente Oriental (unos 4 millones de efectivos, con más de 13.000 hombres/división).

Aunque no hay cifras oficiales, durante el desarrollo del conflicto, el consumo de vodka se estima como: el $20 \%$ de los soldados estarían en la línea de combate; se entregarían $100 \mathrm{~cm}^{3}$ al día por cada combatiente; el tiempo considerado en el conflicto sería de tres años, 8 meses y 7 días de enfrentamientos continuos (1342 días aproximadamente). La cifra alcanza a 107.360.000 litros de licor. Para fabricarlo se habrían requerido 356.435 toneladas de papas.

El consumo de papas como comida se calcula para igual número de soldados, con una asignación de $300 \mathrm{~g}$ de papas al día por persona, lo que resulta en un mínimo de 1.610 .400 toneladas métricas. Además comían otros alimentos, en estos análisis se ha considerado que la papa fue uno de los primordiales, pero en mínima cantidad.

El total mínimo de papas para mantener a los soldados combatiendo sería entonces de 1.966 .835 toneladas (como licor y como comida). En las estimaciones no se han considerado las bajas humanas, que eran prontamente repuestas.

\begin{tabular}{lcccc}
\hline Batalla & Duración días & Número soldados rusos & litros vodka & kg papas (alimento) \\
\hline Moscú & 95 & 1.400 .000 & 3.990 .000 & 39.900 .000 \\
Stalingrado & 195 (43 a pleno suministro) & 1.700 .000 & 3.213 .000 & 47.430 .000 \\
Kursk & 21 & 1.300 .000 & 819.000 & 8.190 .000 \\
Berlín & 16 & 2.000 .000 & 960.000 & 9.600 .000 \\
\hline
\end{tabular}

\# Para el consumo de vodka se consideró un 30\% de soldados en la primera línea del frente, con un consumo diario de $100 \mathrm{~cm}^{3}$ por persona. Para alimentación, las papas se estiman $0,3 \mathrm{~kg} /$ persona día. No se consideró al personal de la Fuerza Aérea. 


\section{Conclusiones}

1. Las papas originarias de Sudamérica han tenido posteriormente una importancia vital en la alimentación de pueblos de Europa y el mundo.

2. Viajes a Chiloé de varios botánicos rusos a comienzos y durante el siglo XX dieron las bases para formular que las papas chilotas eran las antecesoras de las variedades cultivadas en la URSS en esas fechas.

3. La actual papa europea descendería de la chilena. Esto se demuestra por recientes investigaciones del ADN (avaladas por importantes organismos internacionales) de especímenes provenientes de antiguos herbolarios de Europa.
4. Las papas y sus derivados constituyeron uno de los alimentos principales que sustentaron al Ejército Rojo durante la Segunda Guerra Mundial, siendo un factor a considerar en la victoria final. Esto generó cambios políticos y sociales en el mundo.

5. Dado el crecimiento de la población mundial y las hambrunas que periódicamente se producen, conviene incentivar las investigaciones sobre variedades que se reproducen en climas extremos y terrenos poco aptos para otros cultivos.

6. Este tubérculo puede cultivarse en terrenos pedregosos y climas fríos como la tundra rusa y el altiplano de la subregión andina, luego es razonable pensar en el empleo de papas para la producción de biocombustibles en zonas extremas.

\section{Literatura Citada}

Poma de Ayala, G.

(1583 a 1613) Nueva Crónica y Buen Gobierno. www.kb.dk/ permalink/2006/poma/info/es/frontpage.htm

Zapater, H.

1973 Los aborígenes chilenos, a través de cronistas y viajeros. Editorial Andrés Bello, 142 págs.

Bukasov, S.

1933 The potatoes of South America and their Breeding Possibilities. Suppl. 58, Bull. Appl. Bot. Genet. Pl. Breed. Leningrad, USSR.

Bukasov, S.

1939 The origin of the potato species. Physis (Buenos Aires) 18: 41-46

Bukasov, S.

1968 Filogeny of the cultivated potato species. N. J. Vavilov. All Union Institute of Plant Industry. Leningrad, USSR. 30 pages

Vavilov, N.

1992 Origin and Geography of Cultivated Plants. Cambridge University Press. 532 pages.

Sykin, A.

1971 Zur Frage der Abstammung und der Wildwachsender Vorfahren chilenischer Kultur Kartoffen. Z. Pflanzenzüchtung 65:1-14
Contreras, A.

2001 Historia de la papa: Mitos y prejuicios. Instituto de Producción y Sanidad Vegetal. Facultad de Ciencias Agrarias. Universidad Austral de Chile. www.andrescontreras.cl/ contenidos/.../index_material.htm

Papas nativas de Chiloé, un patrimonio de la Humanidad. www. papasnativas.cl

Rastreando mediante ADN el origen de la patata moderna. USDA, United States Department of Agriculture, Agricultural Research Service, ARS. www.solociencia.com

Ames, M.; Spooner, D. 2008 DNA from herbarium specimens settles a controversy about origins of European potato. American Journal of Botany, 95 (2):252-257. Agricultural Research Service, Vegetable Crops Research Unit. www.amjbot org/cgi/ content/full/95/2/252

www.1jma.dk/articles/1jmaarticlesvodka.html

Academia Hütte, Berlín. Manual del Ingeniero

1942 Tomo IV. Capítulo V. $2^{\mathrm{a}}$ edición. Editorial Gustavo Gili SA. Barcelona. España. 1581 p.

Beevor, A.

2001 Stalingrado. Editorial Crítica. España. 452 p. 